rank-sum test) and third ( $p<0,0001$, rank-sum test) month, while no differences were recorded at the other time points. Clinical outcomes were similar between the two groups.

Conclusion: Very early introduction of IT in GCA provided a greater steroid sparing in the first 3 months of treatment, leading to a lower incidence of diabetes. Relapse rate was even lower. IT was usually well tolerated without an increase incidence of infections. A randomized prospective trial is required to support this strategy in the management of GCA.

References:

[1] Hellmich B, et al. 2018 Update of the EULAR recommendations for the management of large vessel vasculitis. Ann Rheum Dis. 2020;79:19-30.

Disclosure of Interests: Luca Quartuccio Consultant of: Abbvie, Bristol, Speakers bureau: Abbvie, Pfizer, Miriam Isola: None declared, Dario Bruno: None declared, Elena Treppo: None declared, Laura Gigante: None declared, Francesca Angelotti: None declared, Riccardo Capecchi: None declared, Gianfranco Vitiello: None declared, Elena Cavallaro: None declared, Antonio Tavoni: None declared, Silvia Laura Bosello: None declared, Daniele Cammelli: None declared, Salvatore De Vita Consultant of: Roche, GSK, Speakers bureau: Roche, GSK, Novartis, Elisa Gremese Speakers bureau: Abbvie, BMS, Celgene, Jannsen, Lilly, MSD, Novartis, Pfizer, Sandoz, UCB

DOI: 10.1136/annrheumdis-2020-eular.3085

\section{FRI0217 SENSITIVITY AND SPECIFICITY OF 2019 DCVAS DRAFT CLASSIFICATION CRITERIA FOR GIANT CELLS ARTERITIS AND TAKAYASU ARTERITIS IN A MONOCENTRIC COHORT OF PATIENTS WITH CLINICAL DIAGNOSIS OF LARGE VESSEL VASCULITIS}

F. Regola ${ }^{1}$, A. Tincani ${ }^{1}$, F. Franceschini ${ }^{1}$, P. Toniati ${ }^{1} .{ }^{1}$ Spedali Civili and University of Brescia, Rheumatology and Clinical Immunology Unit, Brescia, Italy

Background: Recently, a new set of classification criteria for Giant Cells Arteritis (GCA) and Takayasu Arteritis (TA) has been developed by the DCVAS project and presented as draft criteria at the 19th International Vasculitis and ANCA Workshop held in Philadelphia in 2019.

Objectives: The purpose of the present study is to analyze the performance of the 2019 DCVAS Draft Classification Criteria in differentiating GCA and TA in a cohort of patients with Large Vessel Vasculitis (LVV), comparing their sensitivity and specificity to 1990 ACR Classification Criteria.

Methods: 2019 DCVAS Draft Criteria and 1990 ACR Criteria were retrospectively applied to a cohort of 130 consecutive patients with Large Vessel Vasculitis. In all patients the diagnosis of vasculitis was histologically and/or radiologically confirmed.

Results: One-hundred patients had a clinical diagnosis of GCA, 25 patients of TA and 5 patients of other form of LVV, different from GCA and TA (idiopathic isolated aortitis $n: 2$, aortitis with retroperitoneal fibrosis $n: 2$, isolated pulmonary arteritis $\mathrm{n}: 1)$.

Among the 100 patients clinically diagnosed as GCA (F/M: 68/32, age: 74 (6083)) only 82 fulfilled the 1990 ACR Criteria for GCA, while all of them fulfilled the 2019 DCVAS Draft Criteria for GCA.

Instead, among the 25 patients with a clinical diagnosis of TA (F/M: 21/4, age: 34 (16-48)), $22(88 \%)$ could be classified as TA according to the 1990 ACR Criteria, $25(100 \%)$ according to 2019 DCVAS Draft Criteria.

In the group of patients diagnosed with other form of LVV (F/M: 2/3, age: 56 (38-71)) 4 patients (80\%) fulfilled the 2019 DCVAS Draft Criteria for GCA, while none of them fulfilled the 2019 DCVAS Draft Criteria for TA or the 1990 ACR Criteria for GCA or TA. One of these patients did not fulfilled any classification criteria.

On the contrary, one GCA patient could be classified both as GCA or TA according to the 2019 DCVAS Draft Criteria but didn't fulfilled the 1990 ACR Criteria for GCA or TA.

For GCA, 2019 DCVAS Draft Criteria shown a sensitivity of $100 \%$ and a specificity of $80 \%$, compared to $82 \%$ and $100 \%$ of 1990 ACR Criteria. For TA, 2019 DCVAS Draft Criteria shown a sensitivity of $100 \%$ and a specificity of $99 \%$, compared to $88 \%$ and $100 \%$ of 1990 ACR Criteria.

For GCA the agreement between the two different sets of criteria was $85.5 \%$ (Cohen's k coefficient: 0.64), for TA the agreement was $85.1 \%$ ( $\mathrm{k}: 0.58$ ).

Conclusion: The new draft classification criteria shown a lower specificity if compared to the older ones, but also a higher sensitivity: in particular 2019 DCVAS Draft Criteria can better identify GCA patients with extracranial involvement, historically excluded from the 1990 ACR criteria.

both GCA and TA 2019 DCVAS Draft Criteria, demonstrating that this classification well performs in differentiating GCA and TA. Table:

\begin{tabular}{|c|c|c|c|}
\hline & GCA $(n: 100)$ & TA $(n: 25)$ & $\begin{array}{l}\text { Other } \\
\text { LVV } \\
(n: 5)\end{array}$ \\
\hline Morning stiffness in shoulders or neck & $43(43 \%)$ & $3(12 \%)$ & $0(0 \%)$ \\
\hline Sudden visual loss & $33(33 \%)$ & $2(8 \%)$ & $0(0 \%)$ \\
\hline Jaw or tongue claudication & $35(35 \%)$ & $0(0 \%)$ & $0(0 \%)$ \\
\hline New headache/ & $77(77 \%) /$ & $5(20 \%) /$ & $1(20 \%) /$ \\
\hline Scalp tenderness & $30(30 \%)$ & $0(0 \%)$ & $0(0 \%)$ \\
\hline Temporal Artery Exam: pathological findings & $34(34 \%)$ & $0(0 \%)$ & $0(0 \%)$ \\
\hline Elevated ESR or CRP & $100(100 \%)$ & $16(64 \%)$ & $5(100 \%)$ \\
\hline Temporal Artery Biopsy: vasculitis & $53(53 \%)$ & $0(0 \%)$ & $0(0 \%)$ \\
\hline Temporal Artery halo sign (US)/ & $11(11 \%) /$ & $0(0 \%) /$ & $0(0 \%) /$ \\
\hline Bilateral axillary involvement & $11(11 \%)$ & $4(16 \%)$ & $0(0 \%)$ \\
\hline FDG-PET activity throughout aorta & $32(32 \%)$ & $13(52 \%)$ & $4(80 \%)$ \\
\hline Angina or ischemic cardiac pain & $5(5 \%)$ & $4(16 \%)$ & $1(20 \%)$ \\
\hline Arm or leg claudication & $5(5 \%)$ & $12(48 \%)$ & $0(0 \%)$ \\
\hline Arterial bruit & $2(2 \%)$ & $19(76 \%)$ & $1(20 \%)$ \\
\hline Reduced pulse in upper extremity & $1(1 \%)$ & $15(60 \%)$ & $0(0 \%)$ \\
\hline Carotid: reduced pulse or tenderness & $0(0 \%)$ & $8(32 \%)$ & $0(0 \%)$ \\
\hline \multirow[t]{2}{*}{ SBP difference in arms: $>10 />20 \mathrm{mmHg}$} & $0(0 \%) /$ & $14(56 \%) /$ & $0(0 \%) /$ \\
\hline & $1(1 \%)$ & $6(24 \%)$ & $0(0 \%)$ \\
\hline Pathological Angiography or AngioCT: & $19(19 \%):$ & $22(88 \%):$ & $5(100 \%)$ \\
\hline number of affected arteries: $1 / 2 />3$ & $7 / 3 / 9$ & $0 / 1 / 19$ & $3 / 0 / 2$ \\
\hline Paired branch arteries involvement & $7(7 \%)$ & $20(80 \%)$ & $2(40 \%)$ \\
\hline $\begin{array}{l}\text { Abdominal aorta with renal or mesenteric } \\
\text { involvement }\end{array}$ & $0(0 \%)$ & $17(68 \%)$ & $0(0 \%)$ \\
\hline
\end{tabular}

Disclosure of Interests: None declared

DOI: 10.1136/annrheumdis-2020-eular.3375

\begin{tabular}{|l|l}
\hline FRI0218 & PREVALENCE, BURDEN OF DISEASE AND \\
HEALTHCARE UTILIZATION AMONG PATIENTS \\
WITH EOSINOPHILIC GRANULOMATOSIS WITH \\
POLYANGIITIS (EGPA) IN JAPAN 2005-2017
\end{tabular}

K. E. Sada ${ }^{1}$, Y. Kojo ${ }^{2}$, J. Fairburn-Beech ${ }^{3}$, K. Sato ${ }^{2}$, E. Hayashi ${ }^{2}$, S. Akiyama ${ }^{2}$, M. Van-Dyke ${ }^{4}{ }^{1}$ Okayama University Graduate School of Medicine Dentistry and Pharmaceutical Sciences, Okayama, Japan; ${ }^{2}$ GSK, Tokyo, Japan; ${ }^{3}$ GSK, London, United Kingdom; ${ }^{4}$ GSK, Collegeville, PA, United States of America

Background: EGPA is a rare vasculitis condition with very limited data available from real-world settings on burden and health care utilization (HCU), particularly in Japan.

Objectives: To estimate the prevalence (overall and age, gender stratified) and describe HCU and treatment patterns among Japanese EGPA patients.

Methods: This was a retrospective descriptive cohort study using a large administrative claims database covering up to more than 5 million corporate employees and their dependents (JMDC claim database) in Japan. Annual prevalence from 2005-2017 was estimated using two EGPA case definitions: a) patients with $\geq 1 \mathrm{ICD}-10$ code (2003 version) for EGPA (M30.1), b) patients with $\geq 2$ ICD-10 codes for EGPA (M30.1) during the year in which prevalence was calculated. Among newly identified EGPA patients with no EGPA code in at least 12 months before, clinical burden, comorbidities, after hour visiting (AHV), all cause hospitalization, and treatment with drugs, including oral corticosteroid (OCS) use was described. OCS dose was expressed as prednisone equivalent.

Results: The total number of newly identified patients in 2006-2016 was 45 persons and the mean (SD) age was 42.3 years (SD 14.7 years). The prevalence (per 1,000,000 patients) of EGPA with case definition a) in Japan in 2017 was estimated to be 38.0 . The stratified prevalence (per 1,000,000) by age was: 2.3 in the group aged $<18$ years, 34.0 in those aged $18-50$ years, and 91.1 in those aged $\geq 50$ years, respectively. The prevalence in females (50.0) was approximately 1.7 -fold higher than that in male (28.7). The prevalence, including stratified results, with definition b) was similar to that with definition a). In the newly identified patients, $60 \%$ of patients had at least one hospitalization and $55.6 \%$ had $\mathrm{AHV}$, in the year after the first observed EGPA code during the study period. Following index date, new patients were treated: $77.8 \%$ with OCS, $11.1 \%$ with Azathioprine, $8.9 \%$ with intravenous immunoglobulin, $6.7 \%$ with Cyclophosphamide, $4.4 \%$ with Methotrexate, and $2.2 \%$ with Rituximab (non mutually exclusive). The mean (SD) maximum recorded daily dose of OCS in the 12 months follow up period was 53.5 (39.9) $\mathrm{mg}$ in new patients. The average dose (SD) of OCS in first month and last month in new patients was 39.1 (29.0) and $9.8 \mathrm{mg}$ (4.8), respectively. Among those with at least a 14-day supply of OCS, $73.1 \%$ could be classified as adherent $(\geq 80 \%)$ based on their 1 -year proportion of days covered. $6.7 \%$ of EGPA patients experienced a potentially worsening with an increase of $\geq 10 \mathrm{mg}$ daily OCS dose prescription following a previous prescription of $<10 \mathrm{mg}$. 